\title{
Social Networks and Entrepreneurship Orientation among Students in Nigerian Universities: A Study of Social Network Size and Risk Disposition
}

\author{
Ameh, Abu Amodu ${ }^{1} \&$ Udu, Aka Ama ${ }^{2}$ Ph.D \\ ${ }^{1}$ Department of Business Administration, Kogi State University, Anyigba, Nigeria \\ ${ }^{2}$ Department of Business Management, Ebonyi State University, Abakaliki, Nigeria \\ Correspondence: Ameh, Abu Amodu, Department of Business Administration, Kogi State University, Anyigba, \\ Nigeria
}

Received: March 8, 2016

Accepted: May 6, 2016

Online Published: May 9, 2016

doi:10.5430/bmr.v5n2p1

URL: http://dx.doi.org/10.5430/bmr.v5n2p1

\begin{abstract}
The study analyzed social networks and entrepreneurial orientation with particular reference to Network of African Student Entrepreneurs in Nigerian Universities. The objective was to explain the relationship between social networks size and risk disposition among student entrepreneurs. Extant literature based on the objective was reviewed. The study adopted descriptive method. Analysis of Variance (ANOVA) was used to analyze the data. The theoretical underpinning is the sociological theory of entrepreneurship particularly the postulations of Frank Young in 1971. The findings revealed that a significant relationship was existing between social networks size and risk disposition among student entrepreneurs in Nigerian universities. If the students in Nigerian Universities fail to key into the revolution epitomized by the Network of African Student Entrepreneurs, then they run the risk of being bereft of entrepreneurial ideas. Consequently, it was recommended amongst others that the leadership of Nigerian Universities should accord the appropriate support by providing logistic support to facilitate its work.
\end{abstract}

Keywords: Social networks, Network size, Entrepreneurship, Entrepreneurship orientation, Risk disposition, Nigerian Universities

\section{Introduction}

Given the need to build a sustainable economy, entrepreneurship has become recognized as one of the major catalysts for economic growth and development. This scenario is even underscored by the growing level of unemployment in Nigeria.

However, the capacity of government to create an enabling environment for enterprises to share information for resource mobilization and encouraging the formation of informal contacts is a major paradigm for economic transformation. This is even underscored by the fact that networks operate in different economic, social or cultural contexts. The success or otherwise of an enterprise depends on the entrepreneurial heightened ability and acute awareness for recognizing business opportunities (David and Nigama 2011). A social network is a social structure made up of nodes ( individuals or organizations) which are linked by one or more specific types of relationship or interdependence such as value, ideas, financial exchange, trade friendship, kinship, social role as well as affection or action relationship ( Haas, 2009)

It is therefore important to focus on how entrepreneurs galvanize relationships to obtain information and resources to run profitable business outfits. Entrepreneurship research shows that social networks among other things affect opportunity recognition (Singh, 2000) as cited in Klyver and Schott (2011). Social networks create a platform to galvanize external information as a source of enhancement for entrepreneurship. That is why Bastian and Tucci (2013) believe that external knowledge supports organizational learning and innovation capabilities, which include skills, experience and organizational structures that are important for change. Social networks are a fundamental necessity for business growth because entrepreneurs interact with other people and by that benefit from access to knowledge, skills and other resources. Greve (1995) in Zafar et al (2012) averred that when entrepreneurs start their business they have a vague idea about how to organize the establishment process, therefore they need the help of the organization who is already existing. These contacts may help to validate business opportunities and provide 
information about the wide firm environment (Hill et al, 1991, 1997) in Bastian and Tucci (2013). It can also follow that entrepreneurial intentions and decisions could be tied to social networks.

The Network of African Student Entrepreneurs (NASE) which has its headquarters in Kaduna State University, is the National Universities Commission (NUC) recognized organization for student entrepreneurship in tertiary institutions in Nigeria. The Network of African Student Entrepreneurs (NASE) is a non-profit organization for students and recent graduates of tertiary institutions that seek to create support for graduates and student entrepreneurs across Africa and the diaspora. Kaduna State University was unanimously chosen as Africa secretariat for the Network of African Student Entrepreneurs (NASE) in far away South end-at-sea campus of the University of Essex, United Kingdom, in June 2010. This was held under the auspices of the Entrepreneurship Partnership for Africa (EPA)- a British Council sponsored project and the National Universities Commission (NUC). The Kaduna State University was mandated to set up a website and coordinate the activities of the Network of African Student Entrepreneurs (NASE) across Africa. This was officially launched in Nigeria by a former Minister of Education; Professor Rukayatu Rufai at the National Universities Commission (NUC) secretariat, Abuja, Nigeria on May 21, 2013. The Network allows peer groups to share information, network and interact on business activities on a well structured interactive platform. The Network of African Student Entrepreneurs (NASE) also provides mentoring and support for young African Entrepreneurs in all universities and graduates across the globe, taking one city, one region, one nation at a time.

\section{Problem Statement}

Entrepreneurs are quite often faced with the challenge of obtaining necessary information for the acquisition of credit for the finance of their businesses, as well as possessing the needed managerial and technical skills and experience required to ensure success in their businesses. This is as a result of information asymmetry or outright lack of it among students in Nigerian Universities, which gives rise to lack of access to useful sources of funds for business. Social networks in Nigerian universities exist and operate in different locations and this diversity should have been a source of diverse information and resources for entrepreneurs. However, the mode of and nature of their operation given the difference in location and diversity may constitute an encumbrance to information sharing, and this is a drawback to entrepreneurship orientation. Absence of sizable and dense networks in Nigerian Universities could prevent entrepreneurs from securing the most suitable sources of information and finance, as could be occasioned by lack of informal contacts, which could have provided support for members. This consequently could preclude the establishment of mutual trust and absence of mutual trust is a major barrier to funding. Similarly absence of membership support and independence in Nigerian universities could mar the acquisition of entrepreneurship orientation by shortening the patronage by members and engendering low level of self-efficacy and innovation respectively. Against the back drop of the information asymmetry, paucity of finance, ineffective mobilization as well as problems associated with the acquisition of entrepreneurship orientation it becomes worthwhile to examine social networks and entrepreneurship orientation with particular focus on network size and risk disposition of entrepreneurs. For this purpose entrepreneurship orientation is dependent on the nature and dynamics of social networks.

\section{Conceptual Review}

Social networks have become essential for entrepreneurship and have also become a major paradigm for the mobilization of resources and the building of trust that is needed in business. They are also a major source of motivation, direction and increased access to new opportunities.

A social network is a social structure made up of nodes (individuals or organizations) which are linked by one or more specific types of relationship or interdependence such as values, ideas, financial exchange, trade friendship, kinship, social role as well as affection or action relationship (Haas, 2009). According to Ogunnaike and Kehinde (2013), social networks are nodes of individuals, groups, organizations, and related systems that tie on one or more types of interdependence: these include shared values, visions and ideas, social contacts, kinship, conflict, financial exchanges, trade, joint membership in organizations and group participation in events, among numerous other aspects of human relationship. This suffices that people of homophilous attributes come together to pursue a common agenda. A social network helps in building trust among the members of the network. This in turn makes it possible for actors to cooperate and expect reciprocation (Rousseau et al, 1998, Dakhli and de Clerg, 2004) as cited in Doh and Zolnik (2011). The trust that has been built will enable the actors to respect the assumed commitment amongst themselves in a particular network. Network interactions can initiate entrepreneurship orientation among the actors. Entrepreneurship social networks help to extend opportunities to one another, share information that could lead to creative and proactive thinking which could ultimately lead to the development of self-worth that engenders further creativity. Entrepreneurship research shows that social networks among other things affect opportunity 
recognition (Singh, 2000) as cited in Klyver and Schott (2011). Network interactions help in building entrepreneurship intentions because as they interact and brainstorm, new idea recognition will begin to develop into new entrepreneurship opportunities. Entrepreneurship orientation refers to the extent to which an individual or team has the propensity for the initiation of new ideas, mobilize resources, take risk and take overall responsibility for actions taken. Simply put by Schillo (2011), it is the extent to which a firm is entrepreneurial. Entrepreneurship orientation can be decomposed into risk disposition (risk taking), pro-activeness, innovativeness, competitive aggressiveness and autonomy. Risk taking according to Stewart et al (1998) in Fairoz et al (2010) is the extent to which a firm is willing to make large and risky resource commitments. Schillo (2011) refers to the risks individuals take by working for themselves rather than being employed. Pro-activeness describes the characteristic of entrepreneurial actions to anticipate future opportunities both in terms of products or technologies and in terms of markets and consumer demand (Schillo, 2011). A proactive entrepreneur is an individual who is focused on the future and anticipates things before they happen.

Innovativeness is the propensity of the firm to engage in new ideas and create processes that may result in new products, services or technological processes (Wiklund, 1999) in Fairoz (2010).It relates to the types of products and services a company has introduced to the market (Schillo, 2011).

Competitive aggressiveness reflects the intensity of a firm's efforts to outperform industry rivals, characterized by a combative posture and a forceful response to competitor actions (Fairoz et al, 2010). It refers to the company's way of engaging its competitors distinguishing between companies that shy away from direct competition with other companies and those that aggressively pursue their competitors' target markets (Schillo, 2011)

Autonomy is defined as independent action by an individual or team aimed at bringing forth a business concept or vision and carrying it through to completion. (Fairoz, 2010)

For the purpose of this paper a social network can be viewed as a set of students, people, groups and organizations who come together to form ties for the purpose of maximizing some form of social impact or profits of stakeholders.

\subsection{Empirical Review}

Entrepreneurship is a major driver of any economy because it injects innovation and economic growth into the economy. In this circumstance, social networks can be one of the key elements for individuals to identify new means ends relationships (commercial opportunities) that result from environment change to discover and exploit entrepreneurial opportunities (Doh and Zolnik, 2011). A good social network is considered as a helpful resource for companies (Zafar et al, 2012).

Stuart and Sorenson (2007) carried out a study on strategic networks and entrepreneurial ventures in the United States of America using qualitative research method. The study revealed that even though literature remains unclear concerning the role of founders and key employee networks, versus the networks of firms, most entrepreneurs and young ventures are strategic in their formation of relations. They recommended that there is need to improve the understanding of how networks form and ascriptive group membership and processes of competitive exclusion shape access to network based resources.

A study on social networks and marketing cooperation in entrepreneurial clusters; an international comparative study was carried out by Felzensztein and Gimmon (2009) in Scotland and Chile. Data for their study was collected by mail survey and follow-up process. The results revealed that social networking is important in facilitating inter-firm cooperation in marketing activities and that informal meetings and weak ties are useful for sharing marketing information among managing directors. They recommended future research to focus on the influence of social networks on the creation and internationalization of new ventures among cluster-based firms.

A study was conducted by Fairoz, Hibrobumi and Tanaka (2010) on entrepreneurial orientation and small and medium scale enterprises of Hambantota district in Sri Lanka, using qualitative and quantitative techniques. The study revealed a significant relationship between proactiveness, innovativeness, risk-taking with overall entrepreneurial orientation with marked share growth. They recommended that government and non-government sector should focus on promoting the level of entrepreneurial orientation by directing research and development activities providing financial resource, training package and consultancy services.

Klyver and Schott (2011) conducted a study on how social networks structure shapes entrepreneurial intention in Denmark using survey method and regression analysis. The study found that only bridging social networks represented by low dense network, business size and entrepreneurial network play an important role in shaping individuals' entrepreneurial intentions. They recommended that the policy makers aiming at stimulating entrepreneurial activities should promote networking. 
A study on the influence of social capital on entrepreneurial opportunity recognition behaviour was carried out by Jawahar and Nigama (2011) in India using survey and regression analysis. The study revealed that the structural dimension of social capital is the most important in influencing knowledge acquisition behaviour of opportunity recognition. They recommended that it is imperative to recognize, evaluate and exploit opportunities from a lot of decision choices.

Zafar, Yasin and Ijaz (2012) carried out a study on social networking as a source for developing entrepreneurial intentions among entrepreneurs in Pakistan using survey and critical analysis procedure. The study revealed that social networking helps the entrepreneurs in developing entrepreneurial intention. They recommended that universities should create network nexus through old students (Alumni) that might develop into business.

Kacperczyk (2012) carried out a study on social influence and entrepreneurship; the effect of university peers on entrepreneurial entry in United States of America using survey method and logistic regression models. The study revealed that among individuals exposed to similar organizational influence, those exposed to entrepreneurial university peers are more likely to transit to entrepreneurship.

Konrad (2013) conducted a study on cultural entrepreneurship. The impact of social networking on succession in Germany using survey and regression analysis. The study revealed that founders as well as managers can overcome numerous barriers through their engagement and activity in social networks, and thereby exercise to a significant degree a positive influence on establishing their enterprise. He recommended a more detailed analysis of the barriers and the beneficial potential especially for the very complex arts and culture sectors of different countries.

\subsection{Levels of Social Network}

Nahapiet and Ghosal (1997) as cited in Tsal and Ghosal (1998) identified three dimensions or levels of social networks. These are structural, relational, and cognitive. They theoretically justified how attributes of each of these dimensions facilitate the combination and exchange of resources within firms. According to this view the structural dimension includes social interaction. The location of an actor's contact in a social structure of interactions provides certain advantages for the actor. The relational dimension on the other hand refers to assets that are rooted in these relationships, such as trust and trustworthiness. Trust can act as a governance mechanism for embedded relationships (Uzzi 1996) as cited in Tsal (1998). Trust is an attribute of a relationship, but trustworthiness is an attribute of an individual actor involved in the relationship (Barney and Hansen, 1994) as cited in Tsal and Ghosal (1998). The cognitive dimension is embodied in attributes like a shared code or a shared paradigm that facilitates a common understanding of collective goals and proper ways of acting in a social system.

\subsection{The Link between Network Size and Risk Disposition}

Social networks promote the propensity for risk taking because, the close association and interaction that characterize social networks are a potential source of information, and the availability of information puts the entrepreneur on a proper pedestal for risk taking as more support is also enjoyed. According to Klyver and Schott (2011), trust between actors increases the likelihood that the entrepreneur may obtain sensitive information and emotional support. The emotional support which will eventually remove fear will serve as a source of courage for risk taking. For example fear has a distinct effect on risk preferences, increasing risk-aversiom (Lerner and Keltner, 2001) as cited in Kashdan et al (2006). This position is also bolstered by Kashdan (2006), that individuals with excessive social fears tend to be most risk-aversive in social contexts. In a study on the role of social networks and adult health conducted by Martire and Franks (2014), the findings suggested that health related social interactions among network members, more so than network characteristics, may be a key mechanism through which social ties are linked with engagement in health or risk promoting behavior. Lechner (2005) also averred that networking is strongly needed to develop entrepreneurial capabilities since networking enhances learning. The importance of information to entrepreneurship cannot be overemphasized. To be able take risk appropriately, the entrepreneur needs useful information which social networks as a platform generates.

\subsection{Entrepreneurship Orientation}

Entrepreneurship orientation refers to the extent to which a firm is entrepreneurial (Schillo, 2011). Lumpkin and Dess (1996) as cited in Putri (2009) refer to a firm's entrepreneurial orientation as its propensity to act autonomously, innovate, take risk, and act proactively when confronted with market opportunities. Schillo (2011) refers to entrepreneurial orientation as having five components. These are:

Risk taking- this refers to the risks individuals take by working for themselves rather than being employed. It is the extent to which a firm is willing to make large and risky resource commitment (Stewart, et al, 1998; Covin and Slevin, 1991) in Fairoz, Hirobumi, and Tanaka 2010). Pro-activeness- describes the characteristic of entrepreneurial 
actions to anticipate future opportunities, both in terms of products or technologies and in terms of market and consumer demands. It refers to the extent to which a firm is a leader or follower and is associated with aggressive posturing relative to competitors (Davis, et al, 1991) in Fairoz, et al (2010). Innovativeness- relates to the types of products and services a company has introduced to the market. Competitiveness- refers to the company's way of engaging with its competitors, distinguishing between companies that shy away from direct competition with other companies and those that aggressively pursue their competitor's target markets.

Autonomy- refers to the independent action of an individual or a team in bringing forth an idea or a vision and carrying it through to completion (Lumpkin and Dess, 1996) as cited in Schillo (2011) without being held back by overly stringent organizational constraints.

\subsection{Strategies for Inculcating Entrepreneurship in Nigerian Universities}

One of the greatest challenges facing entrepreneurship is the strategies for inculcating the expected entrepreneurial skills to students. But given the economic realities of our economy, there must be a strategy to ensure that entrepreneurship culture is imbibed in Nigeria. According to Mansor and Othman (2011) since each higher institution is having its own activities and programmesa on entrepreneurship education, the best and effective programmes need to be identified and created to ensure that all institutions are given fair opportunities to prepare the best methods on entrepreneurship education. But the way entrepreneurship in Nigerian universities is run currently leaves much to be desired, as it has failed to go beyond classroom theory. In the words of Mansor and Othman (2011), concepts learned in the classroom have minimal real world significance. Education and knowledge cannot be delivered solely from text books and lectures; it must include practical, hands-on experience that challenges the students especially in entrepreneurial studies (Asmah and Ariffin, 2009) in Mansor and Othman (2011). The lecture method as is presently done in Nigerian universities will hardly achieve the aims of entrepreneurship education. According to Jimoh-Kadiri (2012) lecture method is inappropriate when the objective is to transfer skills and change attitude. Daly (2001) in Jimoh-Kadiri (2012) suggested four methods namely seminars, visitation, intern challenge and practice firm. Jimoh-Kadiri (2012) believes that strategies could also be teacher-oriented, student-oriented, assignment-oriented and games and simulation. It is important that any strategy for inculcating entrepreneurship education should be practice-based so that graduates of Nigerian universities can have the opportunity of aligning the theory with the practical world experience

\subsection{Challenges and Barriers to Network of African Student Entrepreneurs (NASE)}

Top management support- the level of support currently enjoyed by NASE in Nigerian universities is at a low ebb. For this body to succeed in its laudable mission, the top management of the universities must be favorably disposed to providing financial and material support for the prosecution of its programmes.

Lack of investment culture among the students- the students generally feel it is not worthwhile to be fully committed to this organization since membership does not contribute to their graduation from the university, as the programme is not credit rated.

Novelty character dilemma-the challenge of misconception of social networks as epitomized by NASE as an individualistic effort rather than a collectivistic one because of lack of awareness about its prospects and relevance to the immediate environment should be surmounted. Other barriers include the creation and maintenance of atmosphere of trust and reciprocity with respect to the sharing of information and business opportunities.

The above challenges not withstanding, NASE has come to stay as it has global acceptability for valuable service to the immediate environment.

\section{Theoretical Framework}

Social networks as an interactive platform for information sharing and networking must be viewed with a holistic perspective so as to leverage on the benefits that they deliver to members. Because organizations and their members are changing and complex, numbers of their attributes should be studied together and as a matter of degree, not as neither/or phenomena-a multivariate approach to a changing world of greys, rather than blacks and whites ( Pugh and Hickson, 2007). This suggests that there is no one reason why an organization is established and run but on the basis of many influences. What determines the nature and form that an organization takes is its size and degree of dependence on other existing organizations. This suffices that an organization must interact on a synergistic basis for business promotion. The theory that provides the basis for this study is the Frank Young's sociological theory of entrepreneurship propounded in 1971. The Young's theory is based on the following assumptions, that a group is seen to be experiencing low status recognition, denial of access to important social networks and possesses a greater range of institutional resources than other groups in society at the same system level, negative displacement- losing 
job for instance, transition from college or the university to career, positive pull- examples made by parents, friends and mentors and activated by situations that positively affect the individual, perceptions of desirability- message from society, culture, friends, situations, peers and mentors as well as perceptions of feasibility including support from mentors and partners. Udu and Udu (2015) further averred that the need to work harder and measure up will bring in creativity, innovation, vision and plain hard work. Udu and Udu (2015) opine that Frank Young concerned himself with inter group relations as the main causes of entrepreneurial behaviour. According to Young (1971) instead of individuals, one must find clusters which may qualify themselves as entrepreneurial groups, as the groups with higher differentiation, and have the higher capacity to react. Young defined reactiveness or solidarity as the degree to which the members of the group create, maintain and project a coherent definition of their situation. And differentiation Young defined as the diversity, as opposed to coherence, of the social meanings maintained by the group. When a group has a higher degree of institutional and occupational diversity relative to its acceptance, it intends to intensify its internal communication which gives rise to a unified definition of the situation (Deshpande, 1982) in Pawar (2013). Young maintains that entrepreneurial activity is generated by the particular family backgrounds, experiences, as a member of a certain kind of groups and as a reflection of general cultural values.

The inter group relations as emphasized by the Frank young's theory, which is characteristic of social networks provides an appropriate platform for information and idea sharing, which ultimately bolsters entrepreneurship orientation. Inter group relations is also a major paradigm for resource mobilization and the building of mutual trust that is needed in business. Therefore the theory is considered appropriate for the present study.

\section{Methodology}

Questionnaires were designed as instruments for data collection using the five point Likert's scale ranging from strongly agree $=5$, agree $=4$, disagree $=3$ strongly disagree $=2$ and undecided $=1$. A sample of 94 students was arrived at from a population of 123 students using the Taro Yamane formular. The samples were randomly selected. Analysis of Variance (ANOVA) was used in analyzing the data with a level of significance of 5\%. When it is compared with the probability value obtained from the ANOVA result, it is such that if the probability value falls below 0.05 , it implies that there is a strong relationship between the identified variables of the study. Likewise using the rule of thumb of 2, an F-stat value that is greater than 2 suggests a significant relationship, but if it falls below 2, it implies there is no significant relationship between the variables of the study.

\section{Limitation}

The quality of a study is a function of the accuracy and reliability of the sources of data to be used. The limitations encountered range from the difficulties associated with data collection, design of the study, sample size and sampling technique as well as failure on the part of the respondents to return some of the questionnaires on time as occasioned by the usual excuse of time constraint. However, the researcher overcame the expected limitations through enabling the respondents to understand that their responses will be treated confidentially and upon request, the final document will be made available to them. 


\section{Analysis of the Questionnaires and Results}

Table 1. The Relationship between Social Network size and Risk disposition

\begin{tabular}{|c|c|c|c|c|c|c|}
\hline \multirow[t]{2}{*}{$\mathbf{S} / \mathbf{n}$} & \multirow[t]{2}{*}{ Questions } & \multicolumn{5}{|c|}{ No of Respondents } \\
\hline & & $\underline{\mathrm{SA}=5}$ & $\underline{A=4}$ & $\underline{\mathrm{D}=\mathbf{3}}$ & $\underline{\mathrm{SD}=2}$ & $\underline{\mathrm{U}=1}$ \\
\hline 1. & $\begin{array}{l}\text { Network size affects the risk disposition to a } \\
\text { great extent. }\end{array}$ & $61(64.89 \%)$ & $31(32.98 \%)$ & $1(1.06 \%)$ & - & $1(1.06 \%)$ \\
\hline 2. & $\begin{array}{l}\text { A high number of ties in a network affects } \\
\text { risk disposition positively. }\end{array}$ & $56(59.57 \%)$ & $35(37.23 \%)$ & $3(3.19 \%)$ & - & - \\
\hline 3. & $\begin{array}{l}\text { Members with large networks have better } \\
\text { access to information and resources than } \\
\text { those with smaller networks and favourably } \\
\text { disposed to risk taking. }\end{array}$ & $59(62.77 \%)$ & $34(36.17 \%)$ & $1(1.06 \%)$ & - & - \\
\hline 4. & $\begin{array}{l}\text { Contacts with entrepreneurs outside the } \\
\text { network enhances risk taking }\end{array}$ & $43(45.74 \%)$ & $45(47.87 \%)$ & $4(4.25 \%)$ & $2(2.13 \%)$ & - \\
\hline 5. & $\begin{array}{l}\text { Contacts with members of other networks } \\
\text { enhance disposition toward risk taking. }\end{array}$ & $47(50 \%)$ & $44(46.81 \%)$ & $3(3.19)$ & - & - \\
\hline
\end{tabular}

SOURCE: FIELD SURVEY, FEBRUARY, 2016

From the table above, results in question 1 showed that majority of the respondents, which is 61 representing $61.89 \%$ of the total respondents for the study strongly agree that there is a strong relationship between network size and disposition toward risk taking. 31 of the respondents representing $32.98 \%$ of the total respondents for the study also agreed that there is an existing relationship between network size and the disposition of entrepreneurs toward taking risk. 1 of the respondents representing $1.06 \%$ of the total respondents for the study however disagreed that there exists a relationship between network size and the disposition of entrepreneurs toward taking risk, 1 respondent representing $1.06 \%$ was undecided about whether there is a relationship between network size and risk disposition. From the above majority view it can be affirmed that there is a strong relationship between network size and the disposition toward taking risk in entrepreneurship.

From question 2 above, 56 respondents representing $59.57 \%$ of the total respondents for the study strongly agree that a high number of ties in a network affects risk disposition positively. 35 respondents representing $37.23 \%$ of the total respondents for the study agreed that a high number of ties in a network positively affects risk disposition amongst entrepreneurs. 3 respondents representing $3.19 \%$ of the respondents for the study however disagreed, that a high number of ties in a network does not necessarily encourage risk disposition toward risk taking. From this majority view, it can be affirmed that a high number of ties in a network will affect risk disposition positively.

From question 3 above, 59 respondents representing $62.77 \%$ of the total respondents for the study strongly agree that members with large networks have better access to information than those with smaller networks and will consequently be disposed to risk taking. 34 respondents representing $36.17 \%$ of the total respondents for the study agreed that members with large networks will have better access to information than those with smaller networks and will consequently be favourably disposed to risk taking. 1respondent representing $1.06 \%$ of the total respondents for the study however disagreed, that members with large networks will not necessarily have better access to information than those with smaller networks. From this majority view it can be affirmed that members with large networks will have better access to information than those with smaller networks.

From question 4 in the above table, 43 respondents representing $45.74 \%$ of the total respondents for the study strongly agree that contacts with entrepreneurs outside the network will enhance disposition toward risk taking, while 45 respondents representing $47.87 \%$ of the total respondents of the study agreed that contacts with entrepreneurs outside the network will enhance disposition toward risk taking. 4 respondents representing $4.26 \%$ of the total respondents for the study however disagreed that contacts with entrepreneurs outside will enhance risk disposition. 2 respondents representing $2.13 \%$ of the total respondents for the study also had a strong disagreement with the fact that contacts with entrepreneurs outside the network will enhance the disposition of the entrepreneur toward risk taking. From this majority view it can be affirmed that contact with entrepreneurs outside the network will enhance risk disposition. 
From the question 5 in the table above, 47 respondents representing $50 \%$ of the total respondents for the study strongly agreed that contact with members of other networks will enhance the disposition toward risk taking. 44 respondents representing $46.81 \%$ of the total respondents for the study agreed that contact with members of other networks will enhance risk disposition of entrepreneurs toward risk taking. 3 respondents representing 3.19\% of the total population for the study disagreed with the assertion that contact with members of other networks will necessarily enhance risk disposition of entrepreneurs. None of the respondents strongly disagreed nor was undecided about the propriety of contacts with members of other networks enhancing the disposition toward risk taking. From this majority view it can be affirmed that contact with members of other networks will enhance risk disposition.

\section{OBJECTIVE: TO TEST THE RELATIONSHIP BETWEEN SOCIAL NETWORK SIZE AND RISK DISPOSITION}

Test for Equality of Means Between Series

Date: 02/12/16 Time: $15: 27$

Sample: 194

Included observations: 94

\begin{tabular}{|c|c|c|c|c|}
\hline \multicolumn{2}{|l|}{ Method } & $\mathrm{df}$ & Value & Probability \\
\hline \multicolumn{2}{|c|}{ Anova F-statistic } & $(4,465)$ & 3.489411 & 0.0080 \\
\hline \multicolumn{5}{|c|}{ Analysis of Variance } \\
\hline \multicolumn{2}{|c|}{ Source of Variation } & $\mathrm{df}$ & Sum of Sq. & Mean Sq. \\
\hline \multicolumn{2}{|l|}{ Between } & 4 & 5.051064 & 1.262766 \\
\hline \multicolumn{2}{|l|}{ Within } & 465 & 168.2766 & 0.361885 \\
\hline \multicolumn{2}{|l|}{ Total } & 469 & 173.3277 & 0.369569 \\
\hline \multicolumn{5}{|c|}{ Category Statistics } \\
\hline Variable & Count & Mean & Std. Dev. & Std. Err. of Mean \\
\hline Q1 & 94 & 4.617021 & 0.624007 & 0.064361 \\
\hline Q2 & 94 & 4.563830 & 0.559541 & 0.057712 \\
\hline Q3 & 94 & 4.606383 & 0.512596 & 0.052870 \\
\hline $\mathrm{Q} 4$ & 94 & 4.340426 & 0.726654 & 0.074949 \\
\hline Q5 & 94 & 4.468085 & 0.562294 & 0.057996 \\
\hline All & 470 & 4.519149 & 0.607922 & 0.028041 \\
\hline
\end{tabular}

The Probability value of 0.008 obtained falls below 0.05 , i.e. $0.008<0.05$. This implies that there is a significant relationship between social network size and risk operation. Likewise, its F-stat value of 3.49 is greater than 2 i.e. $3.49>2$, it also implies that there is a significant relationship between social network size and risk disposition.

\section{Discussion}

The objective of the paper was to examine the relationship between network size and the disposition toward risk taking by entrepreneurs. The results revealed that there is a strong relationship between network size and the disposition of entrepreneurs toward risk taking in business. This is because of the fact that the bigger the size of the network, the diverse the ties and the more the synergy in terms of information access, resource mobilisation and innovation. According to Martinez and Aldrich (2011), diverse ties increase self efficacy and innovation. They also believed that at the organizational creation stage, most entrepreneurial teams are homogenous whereas team diversity is associated with better outcomes. A high number of ties will also confer diversity on the network which lends credence to the position of the scholars above. Members of large networks are also of the likelihood of getting a wider information base than those of smaller networks because of the myriad of interactions that are available. Contacts with entrepreneurs outside of the network will also enhance risk disposition because of the opportunity to tap from the experience of the entrepreneurs who are already running well established businesses and also for resource mobilisation. This is in line with the position of Greve and Salaff (2003), that establishing a business requires different contacts and resources in different phases. This helps them to build confidence and better ability in business creation. This is also in line with work of Zafar et al (2012), whose study revealed that social networking 
helps in developing entrepreneurial intentions. Contacts of members of one network with members of other networks will also enhance risk disposition because of the experiences they will share, the diversity of information they will access and the promotion of synergy. This is in line with work of Kacperezyk (2012), whose study revealed that among individuals exposed to similar organizational influence, those exposed to entrepreneurial university peers are more likely to transit to entrepreneurship.

\section{Conclusion}

Social networks have become recognized as a major paradigm for entrepreneurial performance in the contemporary business setting. This is because interactions in such networks have come to provide opportunities for resource mobilization and innovation because of the synergy that they confer on actors. The study carried out an analysis of general empirical studies on social networks with a view to explaining the relationship between network size and risk disposition amongst entrepreneurs with particular focus on the Network of African Student Entrepreneurs (NASE), and came to the realization that social networks should be encouraged as they serve as a rallying point, for innovation, resource mobilization and information sharing.

\section{Recommendations}

From the above analysis and conclusion, the following recommendations are plausible.

The management of Nigerian universities should accord NASE the appropriate recognition by providing logistic support by providing infrastructure facilities so that it can expand its activities. The programmes of NASE should be accorded academic recognition by giving it credit units so that students will be encouraged to develop enthusiasm and commitment in its programmes. The alumni association should be encouraged to key into the programmes of NASE in form of partnering with the students for the purpose of promoting the activities of NASE. Every higher institution in Nigeria should key into the laudable programmes of this body as it helps in empowering students for post student life.

\section{References}

Abou-Mghali .A \& Almuala, A. (2012). Impact of Entrepreneurial Networks in the Success of Business on-going Stage in Jordanian Manufacturing Companies. American Academic and Scholarly Research Journal, 4(2), 01-09. URL: http;//www.ccsenet.org/jsd.

Awadh, A.M \& Saad, A.M. (2013). Impact of Organizational Culture and Employee Performance. International Review of Management and Business Research 2(1), pp1-8. URL: http;www.irmbrjournal.com.

Bastian, B. L. \&Tucci, C. L. (2013). The Role of Advice Sources for Entrepreneurship and Innovation. $35^{\text {th }}$ DRUID Celebration Conference 2013, Barcelona, Spain, June 17-19. http://dx.doi.org/jelcodesM13033

Bolton, D.L. \& Lane, N. (2012). Individual Entrepreneurial Orientation; Development a Measurement Instrument. Education and Training 54(2), 219-233. http://dx.doi.org/10.1108/00400911211210314

Borgbatti, S.P \& Forster P.C. (2003). The Network Paradigm in Organizational Research; A Review and Typology Journal of Management 29(6), 991-1013. http://dx.doi.org/10.1016/50149-2063-03-00087-4

Doh, S. \& Zolnik. (2011). Social Capital and Entrepreneurship; An Exploratory Analysis. African Journal of Business Management 5(12), 4961-4975. http://dx.doi.org/10.5897/AJBM11.095

Elmar, D.K. (2013). Cultural Entrepreneurship; the Impact of Social Networking on Success. Creativity and innovation Management, Journal, 22(3), 307-319. http://dx.doi.org/10.1111/caim.12032

Emirbayer, M \& Godwin J. (1994). Network Analysis Culture and the Problem of Agency. American Journal of Sociology, 99(6), 1411-1454. http://dx.doi.org/10.1086/230450

Fairoz, F.M, Hirobumi, T. \& Tanaka, Y. (2010). Entrepreneurial Orientation and Business Performance of Small and Medium Scale Enterprises of Hambantota Distinct, Sri Lanka. Asian Social Science, 6(3), 34-46. URL: http://www.mgt.ruh.ac.ik/staff-index.php?page=5 user=mafasiya

Felzensztein C. \& Gimmon, E. (2009). Social Network and Marketing Cooperation in Entrepreneurial Clusters: An International Comparative Study. Journal of International Entrepreneurship, 01-11. http://dx.doi.org/10.1007/s10843-009-0041-2

Felzensztein, C. \& Gimmon, E. (2007). The Influence of Culture and size upon inter-Firm Marketing Cooperation: A Case Study of the Salmon Farming Industry. Mark Intell Planning, 25(4), 377-393. http://dx.doi.org/10.1108/02634500710754600 
Greve, A. \& Salaff, J. W. (2003). Social Networks and Entrepreneurship. Entrepreneurship Theory and P, Practice, 28(1), pp1-22. Retreived from www,homes.chass-utoronto-ca/ greve/Greve-Salaff

Haas, M. (2009). Social Network Theory and Analysis; A Preliminary Exploration. Centre for Health Economics, Research and Evaluation, Faculty of Business, University of Technology, Sydney. URL: https;//www.rrstq.com/fra/publications/social-network-theory-and-analysis-a-premilinary-exploration.asp.

Hooi, P. (2002). The Role of Networking Alliances in Information Acquisition and Its Implications for New Product performance. Journal of Business Venturing, 18(6), 727-744. http://dx.doi.org/1016/S0883-9026(03)00026-0

Jawahar, D.P \& Nigama K. (2011). Influence of Social Capital on Entrepreneurial Opportunity Recognition Behaviour. International Journal of Economics and Management, 5(1), pp351-368. URL: http://econ.upm.edu.my/ijem/vol5no2/bab10.pdf

Jimoh-Kadiri, S.O. (2012). Assessment of Strategies for Effective Teaching of Entrepreneurship by Business Education Teachers in Tertiary Institutions in South-South, Nigeria. An Unpublished Ph.D Thesis, Department of Vocational Education, Nnamdi Azikiwe University, Awka. URL: naulibrary.org/dglibrary/admin/book-directory/thesis/11049.pdf

Kacperezyk J.A. (2012). Social Influence and Entrepreneurship; The Effect of University Peers on Entrepreneurial Entry. Organization Science Articles in Advance, 01-20. URL: olenka.scripts.mit.edu/docs/orsc.1120.0773.pdf

Kilby, P. (2009). Hunting the Heffalump. Social Science Research Network. URL: www.ssrn. com (26/8/2014).

Klyver, K. \& Schott, T. (2011). How Social Network Structure Shapes Entrepreneurial Intentions. Journal of Global Entrepreneurship Research, 1(1), 03-19. URL: ent.ut.ac.ir/jger/images/usersfiles/1/file/pdf/kim\%20kliver\%201.pdf

Kontinen, T. \& Ojala, A. (2011). International Opportunity Recognition Among Small and Medium Sized Family Firms. Journal of Small Business Management, 49(3), 490-514. http://dx.doi.org/10.1111/j.1540-627X.2011.00326.x

Lechner, O.,Dowling, M. \& Welpe, I. (2005). Firm Networks and Firm Development; tHe Role of relational Mix. Journal of Business Venturing, 20. http://dx.doi.org/1016/S0883-9026(03)00026-0

Martinez, M. A. \& Aldrich, H. E. (2011). Networking Strategies for Entrepreneurs; Balancing Cohesion and Diversity. International Journal of Entrepreneurial Behaviour and Research, 17(1), 7-38. http://dx.doi.org/10.1108/13552551111107499

O’Donnell, A. O., Gilmore, A., Cummins, D. \& Carson, D. (2001). The Network Construct in Entrepreneurship Research; A Review and Critique. Management Decision, 39(9), 749-760. http://dx.doi.org/10.1108/EUM0000000006220

Ogunnaike, O. O. \& Kehinde, O. J. (2013). Social Networking and Business Performance: The Case of Selected Entrepreneurs in Ota, Nigeria. Journal of Business Administration and Management Sciences Research, 2(5), 116-122. URL: http:/www.apexjournal.org/JBAMSR.

Pawar, P. (2013). Social Sciences Perspectives on Entrepreneurship. Developing Country Studies, 3 (9) pp35-38. URL: www.slideshare.net/Alexander Decker/social-sciences-perspectives-on-enterpreneurship-27916101

Putri, N (2009). Literature on Entrepreneurial Orientation. Economics and Innovation Management. www.google.com/nikenputri.

URL: economics-innovations-info.blogspot.com/2009/06/literature-on-enterpreneurial.html.

Schillo, S. (2011). Entrepreneurial Orientation and Company Performance; Can the Academic Literaturer guide Managers? Technology Innovation Management Review, 1-6. URL: www.telfer.uottawa.ca/en/directory/professors/schillo-sandra

Scott, J. (2014). What is Social Network Analysis www.bloomsbury Academic.com (27/4/2014). URL: www.bloomsbury.com/uk/what-is-social-network-analysis-9781849668170/.

Seibert S. E, Kraimer, M.L \& Liden, R.C (2001). A Social Capital Theory of Career Success. Academy of Management Journal, 01-46. http://dx.doi.org/10.2307/3069452

Stuart, E.T\& Sorenson, O. (2007). Strategic Networks and Entrepreneurial Ventures. Strategic Entrepreneurship Journal, 1(1), 211-227. http://dx.doi.org/10.1002/sej.18 
Teoh, W.M \& Chong, S. (2007). Theorizing a Framework of Factors Influencing Performance of Women Entrepreneurship in Malaysia. Journal of Asian Entrepreneurship and Sustainability 3(2), 01-17. URL: www.asianenterpreneurshipjournal.com/AJES1112Teoh.pdf

Tsal, W. \& Ghosal,S. (1998). social capital and value creation: the role of intra firm networks. Academy of management journal, 41(4), 464-476. http://dx.doi.org/10.2307/257085ACAD MANAGE

Udu, A.A, Udu, G.O.C. \& Eze, F.C. (2008). Entrepreneurship. Rhyce Kerex Publishers, 25 Ogunbiyi Lane, Ogui, Enugu-Nigeria.

Zafar, M.J; Yasin, G. \& Ijaz, M. (2012). Social Networking as a Source for Developing Entrepreneurial Intentions Among Entrepreneurs; A Case of Multan. Asian Economic and Financial Review, 2(8), 1072-1084.

URL: http://www.aessweb.com/pdf-files/1072-1084.pdf.

http://www.enactussfu.com/about/

http://www.the bridge.cmu.edu/...in.../about. 